\title{
Lo pedagógico y decolonial en las radios comunitarias Lencas de Honduras
}

\section{The pedagogical and decolonial in the Lencas comunity radios of Honduras}

Wilmer Nahán Díaz Pérez nahan_diaz@yahoo.es

http://orcid.org/0000-0002-9974-2797

Universidad Nacional Autónoma de Honduras (Honduras)

\section{Resumen}

Las comunidades indígenas hondureñas, históricamente han sufrido violencias respecto a los elementos que configuran sus identidades culturales. En el caso específico, las comunidades indígenas Lencas han desarrollado un proyecto político de resistencia, ante modelos hegemónicos de desarrollo. Es así que el Consejo Cívico de Organizaciones Populares e Indígenas de Honduras (COPINH), se postula desde el ejercicio histórico de resistencias, mediante la organización, concientización y revalorización cultural desde las comunidades. Dichas prácticas políticas encierran una diversidad de métodos de lucha en defensa de la vida y los bienes comunes y de la naturaleza. Entre ellos resaltan las radios comunitarias, como posibilidad comunicativa y reflexiva en la construcción de conciencias críticas. Estas se amparan en instrumentos internacionales como el convenio Nro. 169 de la OIT y desde la legitimidad política como pueblos originarios. De ese modo, se manifiesta la existencia de 
fundamentos pedagógicos y decoloniales en las concepciones y formas de ejercicio político de las radios desde las comunidades. Entre ellos su facultad educadora, de organización, de memoria histórica, de recuperación de saberes, entre otros.

Palabras clave: Indígenas Lencas; radios comunitarias; pedagógico; decolonial.

\section{Abstract}

The Honduran indigenous communities, historically have suffered violence around the elements that shape their cultural identities. In that specific case, the Lenca indigenous communities have developed a political project of resistance, in the face of hegemonic models of development. Thus, the Civic Council of Popular and Indigenous Organizations of Honduras COPINH, is postulated from the historical exercise of resistance, through the organization, awareness and cultural revaluation from the communities. The political practices include a diversity of methods of struggle in defense of life, commongoods and nature. Amongthem, community radios stand out as a communicative and reflective possibility in the construction of critical consciences. These are covered by international instruments such as the ILO Convention No. 169, as well as political legitimacy as indigenous peoples. In this way, the existence of pedagogical and decolonial foundations is manifested in the conceptions and forms of political exercise of the radios from the communities. Amongthem, it's educational, organizational, historical memory, recovery of knowledge, among others.

Keywords: Indigenous Lencas; community radios; pedagogical; decolonial.

La actualidad latinoamericana y en especial las realidades hondureñas, se encuentran inmersas dentro de una cultura del silencio, la que según Freire (1990) se funda cuando "las masas son mudas, es decir, se les prohíbe participar creativamente en las transformaciones de su sociedad, y por ende se les prohíbe ser" (p. 70). Dentro de análisis críticos sobre tal realidad, se manifiesta una naturalización de las violencias, como el caso de los niveles de pobreza más altos de Latinoamérica según la CEPAL (2017), reforzadas en gran medida por instituciones como la educación, la religión y medios de comunicación corporativos.

No obstante, existen instancias educativas, religiosas y de comunicación que se postulan desde la liberación. Concibiendo que la violencia estructural no se comprende como una simple 
mala distribución de los recursos de parte del Estado, sino que como lo refiere Martin-Baró "la violencia estructural supone además un ordenamiento de esa desigualdad opresiva, mediante una legislación que ampara los mecanismos de distribución social de la riqueza y establece una fuerza coactiva para hacerlos respetar" (1990: 406). Por lo que la institucionalidad hondureña no ha podido subsanar las diversas desigualdades sociales. Sino más bien, las legitima y reproduce.

Es claro que existe una violencia generalizada, como lo mencionado respecto a la pobreza, pero además, existen otras circunstancias a nivel comunitario que hacen repensar las diversas formas bajo las cuales se pueden construir proyectos pedagógico-decoloniales, como posibilidades de transformación. De ese modo, el presente ensayo busca generar un marco de reflexión respecto a lo pedagógico y decolonial como fundamentos políticos de las radios comunitarias, especialmente las situadas en comunidades indígenas Lencas, organizadas desde el Concejo Cívico de Organizaciones Populares e Indígenas COPINH. Radios comunitarias, enmarcadas dentro de un proyecto político que se viene organizando y ejerciendo desde 1993, año en que se funda el COPINH.

El marco reflexivo del artículo, desarrollado mediante el estudio etnográfico y la sistematización de experiencias, respecto a defender las resistencias y la resistencia generada desde la praxis política de las radios comunitarias, busca contribuir en la ampliación de la fundamentación histórica y ancestral del COPINH, organización política en defensa de una memoria histórica indígena Lenca, la cual encierra principios tanto de autodeterminación como de legitimidad organizativa; la defensa de los bienes comunes y de la naturaleza; la lucha antirracista, antipatriarcal, etcétera. Además de plantear desafíos pedagógicos a las instituciones educativas formadoras de profesionales de la comunicación desde el periodismo, respecto a cómo estos saberes construidos a nivel comunitario amplían las reflexiones sobre la necesidad de profesionales liberadores de la comunicación. Determinando que el asesinato de Berta Cáceres en 2016 no hizo callar voces, sino más bien, como recita la consigna a nivel de comunidades indígenas, negras, feministas, estudiantiles, etcétera: "Berta no se murió, se hizo millones y por lo tanto Berta soy yo".

\section{Contexto histórico de las radios comunitarias}

Cuando se habla de un marco histórico-político de las radios comunitarias del COPINH como parte de un proyecto pedagógico-decolonial, exige hablar de cómo las radios situadas en 
territorios indígenas Lencas en el occidente del país, entre ellas Radio La voz Lenca, Radio Guarajambala, Radio Gualcarque, Radio Guachipilin y radio La Cuchilla; responden a iniciativas que van más allá del ejercicio como derecho indígena, también responden a una legitimidad histórica, que como comunidades históricamente se les ha negado.

Por siglos, las comunidades indígenas Lencas han venido sufriendo asechanzas de los opresores, colonialistas y del Estado. Actualmente existe una diversidad de resistencias en los territorios por parte de las comunidades organizadas; para comprender tal dimensión de lucha, es necesario hablar de ciertos elementos cosmogónicos configuradores de las espiritualidades y culturas indígenas Lencas. Según el informe desarrollado en 2015, denominado 9/81 "Aproximaciones sobre la situación de derechos humanos de 81 comunidades Lencas", las y los indígenas manifiestan que la tierra es un ser vivo; el río es un ser vivo siendo la sangre de la tierra; el bosque tiene dueños y dueñas ancestrales, como ser el duende dueño de las montañas y los espíritus femeninos cuidadoras de los ríos; la montaña es un ser vivo, una proveedora de agua, viento, oxigeno, frutos, plantas. Además existen múltiples prácticas culturales como el Guancasco, bailes, comidas, etcétera.

La defensa de todos y otros elementos culturales de identidad anteriormente mencionados, se justifican desde dos enfoques. Desde un enfoque de derecho indígena, para ello la Constitución de la Republica (artículo 173 y 346), como también el Convenio 169 de la OIT ratificado por el Estado en 1995 -gracias a extensas movilizaciones y acciones de pueblos indígenas y garífunas en la década de los noventa donde nace el COPINH como organizacióny la Declaración de las Naciones Unidas sobre los Derechos de los Pueblos Indígenas. El segundo enfoque se constituye desde la legitimidad como comunidades originarias, lo que implica comprensiones críticas sobre la memoria histórica de los pueblos, sus posibilidades de autodeterminación y sus formas de hacer pedagogías liberadoras. Las comunidades Lencas, en configuración como pueblo indígena, encierra una manifestación política, espiritual y antropológica del ser indígena, por lo que Cáceres determina que:

En nuestras cosmovisiones somos seres surgidos de la tierra, el agua y el maíz. De los ríos somos custodios ancestrales, el pueblo Lenca, resguardados además por los espíritus de las niñas que nos enseñan que dar la vida de múltiples formas por la defensa de los ríos es dar la vida para el bien de la humanidad y de este planeta (2015).

La existencia de un marco normativo desde los derechos humanos, en aclaración de las responsabilidades del Estado de garantizar, respetar y promover sus culturas, no necesariamente ha significado su aplicabilidad, sino más bien la transgresión sobre los 
diversos territorios, sin antes existir procedimientos respecto a consultas, libres, previas e informadas como bien se menciona en el convenio 169 de la OIT. Por ejemplo, haciendo revisión en el ámbito educativo por medio de las políticas públicas, no existen procesos pedagógicos reales que incentiven críticamente a hablar de una interculturalidad critica, que revalorice el sentido de identidades indígenas, sino más bien existe una exotización hacia las prácticas culturales indígenas. De ese modo, las identidades culturales desde un juicio de memoria histórica, pasa a ser un desafío ético tanto pedagógico como decolonial de organizaciones autónomas como el COPINH; como lo menciona Dussel "de allí que hablar de la eticidad del proyecto pedagógico significa considerar si la meta de la educación es un negar al hijo-pueblo o afirmarlo en su propia exterioridad" (1980: 71).

Por otra parte, existen proyectos extractivos mediante las concesiones de minas, ríos, tierras, bosques, etcétera, sin consentimiento comunitarios. Por lo que empresas nacionales y transnacionales están atentando contra sus territorios. Desde el COPINH, para 2015 se habrían denunciado ante el Ministerio público cincuenta proyectos hidroeléctricos y mineros situados en territorios indígenas, los cuales representan violencias, asesinatos y amenazas a sus diversidades culturales y la madre naturaleza. El ejercicio de poder, realizado por la institucionalidad en no comprender las dimensiones de identidades culturales, al momento de pensar el desarrollo comunitario, no es más que una categoría de imposición colonial eurocéntrica, definida por Quijano como colonialidad, "basada en la imposición de la idea de raza como instrumento de dominación" (1993: 143).

De esa manera, las radios comunitarias se convierten en una de las herramientas de resistencia, pensada y desarrollada para la construcción de conciencia crítica y por lo tanto de la incidencia práctica crítica. Las radios en las comunidades indígenas Lencas se amparan en la Declaración Universal de los Derechos Humanos (1948); en su artículo 19 manifiesta que "todo individuo tiene derecho a la libertad de opinión y de expresión" y lo determinado en el Convenio nro. 169 de la OIT. De esa manera las radios comunitarias como posibilidad comunicativa, desde el COPIHN se manifiestan mediante lo que Cáceres define:

La comunicación es un arma para la formación y capacitación, nos permite la amplitud y diversidad para crear nuevas cosas adecuadas a nuestra realidad, por ejemplo, con las radios comunitarias, pues muchísima gente de nuestra región no sabe leer ni escribir y la radio es esencial. Por ello seguimos en el esfuerzo de fortalecer este eje, que es vital en el proceso político organizativo del COPINH (2016). 
Lo planteado por Cáceres contempla una infinidad de elementos críticos y de resistencia. Ante comunidades hondureñas, que durante décadas han sido marcadas por radios corporativas, las cuales en su mayoría encierran un modelo ideológico alienante respecto a las problemáticas sociales del país. De acuerdo a los planteamientos de Chomsky (2011) uno de los aspectos que utiliza el campo mediático es el emocional más que el reflexivo, en donde "la utilización del registro emocional permite abrir la puerta de acceso al inconsciente para implantar o injertar ideas, deseos, miedos y temores, compulsiones, o inducir comportamientos" (p. 2).

Por ello Selvin Milla, indígena Lenca, militante del COPINH, en una entrevista personal (2015), plantea la diferencia entre una radio comunitaria y una radio comercial o corporativa; enfatizando que la primera se organiza desde la educación popular y la legitimidad comunitaria, es decir, de las propias formas de ejercer lenguaje y comunicación crítica y reflexiva sobre las realidades comunitarias; mientras que la segunda, se apoya en modelos de información en los que el receptor tiene poca posibilidad de reflexionar el discurso manifestado, generando visiones casi unilaterales sobre lo público, y más críticamente, las realidades comunitarias no aparecen como elementos de discusión en dichos medios corporativos.

Desde tales posibilidades de resistencia comunitaria enraizadas en las historias indígenas y negras, es que nace lo pedagógico y decolonial adquiriendo su sentido "político, social, cultural y existencial, como apuestas accionables fuertemente arraigadas a la vida misma y, por ende, a las memorias colectivas que los pueblos indígenas y afrodescendientes han venido manteniendo como parte de su existencia y ser" (Walsh, 2014: 8). Asumiendo roles políticos que traspasan la individualidad del ser, hacia una colectividad del ser en consonancia con lo social y demás seres que habitan en la tierra. De ese modo "el 'estar' implica algo más que su mera enunciación no dice" (Kusch, 1976: 157), por ello las diferencias culturales concluyen en la posibilidad del reconocimiento de las y los otros desde sus legitimidades de auto determinarse como tal, el otro histórico. Dichos procesos, enfatizados en la recuperación de lo cultural, evidencian que "en realidad ningún colonizado, ya sea como individuo o como nación, sella su liberación, conquista o reconquista su identidad cultural, sin asumir su lenguaje, su discurso, y ser asumido por ellos (Freire, 1994: 213).

Tales reivindicaciones han llevado a la amenaza, asesinatos y persecución a quienes generan dichas posibilidades comprensivas, desde categóricas históricas y de liberación. Casos específicos son el asesinato de Berta Cáceres en 2016 y Tomás García en 2013, entre otras y otros indígenas Lencas, sobre todo a raíz de la resistencia contraconstrucción de la hidroeléctrica, Agua Zarca en el Rio Gualcarque Intibucá, proyecto instaurado sin consultar a las comunidades. De la misma manera, existe la amenaza física sobre los instrumentos 
técnicos de las radios comunitarias, por parte de Comisión Nacional de Telecomunicaciones (CONATEL), negando lo declarado por medio del Convenio 169, como también por parte de instituciones religiosas, como por ejemplo, el señor "Cardenal Oscar Andrés Rodríguez hizo un Ilamado durante una visita al Departamento de Lempira para que no se organicen ni escuchen las radios comunitarias del COPINH" (Pasos de animal grande, 2016).

\section{Lo temático de las radios comunitarias}

Lo temático, o los temas generadores sobre el qué decir en las radios comunitarias, anteceden a la necesidad política de las comunidades respecto a las formas de comunicar, y en esa medida cómo generar reflexividad que lleve al accionar político. De ese modo aparece la memoria histórica como principio, desde la que se recuperan todos aquellos saberes originarios de los pueblos que históricamente han sido negados por la institucionalidad colonial y moderna, como lo es la escolaridad. Recuperar saberes significa una desobediencia epistémica, por lo que pensar decolonial exige "un vuelco epistémico y la afirmación del 'ser donde se piensa' en lugar de saber que se existe porque se piensa" (Mignolo, 2010: 93).

Lo temático y los diversos saberes manifestados en la práctica radial se manifiestan de distintas formas. Para ello se discuten y comunican temáticas, como lo manifiesta Gaspar Sánchez, indígena Lenca, militante del COPINH y coordinador de la Secretaría de diversidad sexual, en una entrevista personal realizada en 2016, mencionando que desde las radios se problematizan ejes como el ser indígena y los derechos internacionales y nacionales que les amparan; la memoria histórica respecto a los más de 500 años de colonización; la soberanía alimentaria como posibilidad política de autogestión, de relación espiritual con la tierra; feminismo, como Berta Cáceres lo pronunció, respecto al colonialismo patriarcal y capitalismo patriarcal como categorías históricas prevalecientes en la colonialidad actual; la diversidad sexual, como tema que ha venido siendo casi mitológico en los territorios indígenas; la recuperación y la defensa de los territorios, como posibilidad tanto comunicativa como de construcción cultural y espiritual de comunidad; el extractivísmo de agua, minerales y oxígeno en comunidades; temáticas de realidad nacional e internacional; interculturalidad en la medida que otras radios y otros pueblos conocen los procesos políticos del COPINH, entre otros temas que surgen en la medida que existen problemáticas comunitarias. De esa forma, "de aprendizaje en aprendizaje se va fundando una cultura de resistencia" (Freire, 1994: 134). 
Los ejes temáticos comunicativos desde las radios se fundamentan metodológicamente desde la educación popular, desde las y los indígenas Lencas manifestándose con "su lenguaje que, emergiendo de su realidad y volviéndose hacia ella, perfila las conjeturas, los diseños, las anticipaciones del mundo nuevo" (Freire, 1994: 59). En donde las experiencias y la condición política de las comunidades son transmitidas, no como verdad absoluta, sino como posibilidad transformadora, como un diálogo intercultural crítico, en la cual la diversidad y la deferencia "se construye dentro de una estructura y matriz colonial de poder racializado y jerarquizado" (Walsh, 2009: 4).

\section{Conclusiones}

Desde las comunidades indígenas Lencas existe una resistencia construida en esperanza política. La anuencia del Estado en asumir la responsabilidad de promover, respetar y garantizar los derechos indígenas ha despertado a las comunidades desde la legitimidad histórica de organizarse. De esa manera se hace educación crítica, concientizando y asumiendo roles protagónicos en defensa de los territorios, la vida y todo ser que cohabita en la madre naturaleza. La construcción de la información y la comunicación a partir de los diversos elementos que caracterizan la identidad cultural Lenca, se han venido realizando desde diversos espacios y estrategias. De esa forma, las radios comunitarias organizadas desde el COPINH se manifiestan como posibilidades populares tanto en la revalorización y recuperación de las memorias y culturas, como también como medio crítico para la convocatoria, organización y concientización.

La práctica generada desde las distintas radios se da mediante el amparo en convenios internacionales como el nro. 169 de la OIT sobre pueblos indígenas, relacionado a que estos están en el pleno derecho de construir sus propios medios de comunicación. No obstante, existe todo un proceso de criminalización, amenaza y asesinatos para quienes defienden territorios ancestrales y a quienes inciden desde radios comunitarias. Caso reciente: el asesinato de Berta Cáceres en 2016, cofundadora del COPINH y coordinadora de la misma, Tomas García y otros y otras en años anteriores. Las radios comunitarias vienen sufriendo una serie de atentados físicos, materiales y amenazas directas a quienes las dirigen. Casos que evidencian que las acciones generadas desde la comunicación alternativa, encierra una diversidad de principios y procesos pedagógicos decoloniales. 
Los diversos temas de concientización respecto de la recuperación de culturas, saberes y formas de organización comunitaria, exige de parte de quienes problematizan las radios comunitarias las comprensiones esenciales tanto a niveles técnicos sobre manejo y mantenimiento de equipos; como también manejo de temáticas atenuantes a las realidades comunitarias, por ejemplo: soberanía alimentaria, derechos indígenas, feminismo, diversidad sexual,interculturalidad critica, luchas latinoamericanas, análisis de realidad nacional, cambio climático, impacto en las cosmovisiones y seres vivos desde la minería y represas hidroeléctricas; entre otra diversidad de temáticas concernientes al enfoque decolonial y de liberación latinoamericano. Temáticas que no son centrales en el currículo y procesos educativos formales, como tampoco en los medios de comunicación corporativos. Por último exige la comprensión de la educación popular como posibilidad metodológica critica para la problematización de tales temáticas.

Una de las formas de resistencia en las radios comunitarias, es la transversalidad de estas por medio de diálogos interculturales con otros procesos liberadores, tanto nacionales como internacionales; en los cuales se comparten principios, temáticas, metodologías y formas constitutivas de lo pedagógico y decolonial. Las radios comunitarias se convierten entonces en el anuncio desde la denuncia y por lo tanto esperanza desarrollada por el COPINH y manifestada por Cáceres (2015) al convocar diciendo “¡Despertemos! ¡Despertemos Humanidad! Ya no hay tiempo. Nuestras conciencias serán sacudidas por el hecho de solo estar contemplando la autodestrucción basada en la depredación capitalista, racista y patriarcal".

Todo lo planteado desafía a los campos formales de la comunicación y periodismo, en relación directa con los distintos programas académicos en los cuales se enfatizan currículos en la aprehensión de lo que significa la comunicación desde el periodismo. Por ello, es necesario plantear interrogantes respecto a: ¿cómo, desde la universidad, se pueden recuperar estos saberes comunitarios y ser planteados a nivel curricular y práctica andragógica? ¿Cuál es la importancia de estos saberes comunitarios para la formación de profesionales de la comunicación? Entre otras preguntas necesarias para la investigación social y para acciones políticas críticas. 


\section{Bibliografía}

Cáceres, B. (2016). Copinh Honduras. Recuperado de https://copinh.org/2016/08/\%C2\%A1amplifiquemos-nuestras-voces/

Careces, B. (20 de abril de 2015). Discurso. Premio Ambiental Goldman. San Francisco, California, EUA. Recuperado de http://www.radiomundial.com.ve/article/discurso-deberta-c\%C3\%A1ceres-al-recibir-premio-ambiental-goldman

Chomsky, N. (2011). Diez estrategias de manipulación mediática. Archipielago, 7-8.

COPINH (2015). Aproximaciones sobre la situación de derechos humanos en 81 comunidades Lencas, miembras del COPINH y sus resistencias. Intibuca: Popular.

COPINH (2 de junio de 2018). Consejo Cívico de Organizaciones Populares e Indígenas de Honduras. Obtenido de ¿Quiénes somos? Recuperado de https://copinh.org/quienessomos/

Dussel, E. (1980). La pedagógica latinoamericana. Bogotá: Nueva América.

Freire, P. (1994). Pedagogía de la esperanza. México: Siglo XXI.

Freire, P. (1990). La naturaleza política de la educación. Cultura, poder y liberación. Barcelona: Ediciones Paidós Ibérica S.A.

Kusch, R. (1976). Geocultura del hombre americano. Buenos Aires: Colección Estudios Latinoamericanos.

Martin-Baró, I. (1990). Acción e ideología. Psicología Social desde Centroamérica. San Salvador: UCA editores.

Mignolo, W. (2010). Desobediencia epistémica: retórica de la modernidad, lógica de la colonialidad y gramática de la descolonización. Buenos Aires: Ediciones del Signo.

Organización Internacional del Trabajo (1989). Convenio Núm. 169 sobre Pueblos Indígenas y Tribales en países independientes. Ginebra.

ONU (1948). Declaración Universal de los Derechos Humanos. Paris: ONU.

Pasos de animal grande (27 de abril de 2016). Amenazas a la libertad de expresión. Recuperado de https://bit.ly/2zGXvvH

Quijano, A. (1993). Colonialidad del poder, eurocentrismo y América Latina. En Lander, E. La colonialidad del saber: eurocentrismo y ciencias sociales. Perspectivas latinoamericanas (pp. 122-152). Buenos Aires: CLACSO.

Walsh, C. (2014). Lo pedagógico y lo decolonial: entretejiendo caminos. Queretano: COPYLEFT. 